\title{
SARS-CoV-2 and Obesity: "CoVesity"—a Pandemic Within a Pandemic
}

\author{
Kimberley Zakka ${ }^{1}$ - Swathikan Chidambaram ${ }^{2} \cdot$ Sami Mansour $^{3} \cdot$ Kamal Mahawar $^{4} \cdot$ Paulina Salminen $^{5}$. \\ Ramos Almino ${ }^{6}$. Philip Schauer ${ }^{7}$. James Kinross ${ }^{3}$. Sanjay Purkayastha ${ }^{3}$ (D) - on behalf of the PanSurg Collaborative
}

Received: 25 June 2020 /Revised: 9 August 2020 / Accepted: 11 August 2020 / Published online: 22 January 2021

(C) The Author(s) 2021

\begin{abstract}
Individuals who are overweight or suffering from obesity are in a chronic state of low-grade inflammation, making them particularly susceptible to developing severe forms of respiratory failure. Studies conducted in past pandemics link obesity with worse health outcomes. This population is thus of particular concern within the context of the COVID-19 pandemic, considering the cessation of obesity management services. This systematic review highlights [1] the reciprocal link between the obesity and COVID-19 pandemics, [2] obesity as a risk factor for more severe disease in past pandemics, [3] potential mechanisms that make individual's suffering from obesity more susceptible to severe disease and higher viral load, and [4] the need to safely resume bariatric services as recommended by expert guidelines, in order to mitigate the health outcomes of an already vulnerable population.
\end{abstract}

Keywords Obesity $\cdot$ Coronavirus $\cdot$ SARS-CoV-2 $\cdot$ COVID- $19 \cdot$ Bariatric surgery $\cdot$ Obesity surgery $\cdot$ BMI

\section{Introduction}

On March 11 2020, Coronavirus Disease-2019 (COVID19) caused by the novel severe acute respiratory syndrome coronavirus (SARS-CoV-2) was declared a global pandemic by the World Health Organization (WHO) [1]. Several conditions have been associated with more severe presentations and hospital admissions, including age,

Kimberley Zakka and Swathikan Chidambaram contributed equally to this work.

Sanjay Purkayastha

s.purkayastha@imperial.ac.uk

1 Faculty of Medicine, American University of Beirut, Beirut, Lebanon

2 Oxford University Clinical Academic Graduate School, Medical Sciences Office, University of Oxford, Oxford, UK

3 Department of Surgery and Cancer, Imperial College London, St Mary's Hospital, Academic Surgical Unit, 10th Floor QEQM, South Wharf Road, London W2 1NY, UK

4 Sunderland Royal Hospital, Sunderland, UK

5 Department of Surgery, Turku University, Turku, Finland

6 Gastro-Obeso-CIMO, Sau Paulo, Brazil

7 Pennington Biomedical Research Institute, Baton Rouge, LA, USA male gender, obesity, hypertension, diabetes, cardiovascular disease, and chronic lung disease [2]. Recent studies have reported obesity as an independent predictive factor for worse outcomes, increased complications, and intensive care therapies [3]. While these findings enable clinicians to identify at-risk patients more promptly, it also emphasizes the neglected pre-existing obesity pandemic. The WHO estimates that obesity rates have nearly tripled worldwide since 1975 [4]. As of 2016, approximately 1.9 billion people are overweight with a body mass index (BMI) of 25-30, and over 650 million are obese with a BMI $>30$ [4]. Together, this brings the global obesity rate in adults to about $45 \%$.

Several authors have suggested a link between pandemics and subsequent increases in obesity rates [5-9]. The lockdown culture, changes in food-seeking behavior, and more sedentary home-based activities might, in effect, further worsen the obesity pandemic. The cessation of obesity management services including bariatric surgery during the pandemic could further aggravate the situation. Given suggestions that the COVID-19 pandemic may never go away, it would be particularly useful to know how individuals with obesity are faring during this viral pandemic. If they are experiencing a worse outcome, it might highlight an urgent need to double our efforts aimed at combating obesity. 
To our knowledge, there is currently no systematic review in the scientific literature examining the relationship between obesity and COVID-19 pandemics. The purpose of this systematic review was to evaluate the outcomes of COVID-19 patients suffering from obesity, and the effect of the COVID19 pandemic on the obesity pandemic itself, in accordance with the Preferred Reporting Items for Systematic Reviews and Meta-Analyses (PRISMA) guidelines [10].

\section{Methods}

\section{Search Strategy and Selection of Studies}

Scientific publications related to the relationship between obesity and COVID-19 infections were identified using MEDLINE, EMBASE, the Cochrane Review, and Scopus databases. Our search terms included "coronavirus" OR "COVID 19" OR "COVID-19," "COVID-19" OR "novel coronavirus" OR "SARS-CoV-2" OR "nCoV19” OR "2019nCoV" and a separate search using the terms "obes*" OR "overweight*" OR "over-weight*" OR "obesity" OR "BMI" OR "body mass index" OR "adipos*" OR "bariatric surgery" OR "metabolic surgery." Both strings were combined using the AND modifier. The search included studies published up to May 16, 2020. The reference lists of eligible articles were also hand-searched for additional relevant publications.

\section{Selection of Studies: Inclusion and Exclusion Criteria}

Inclusion and exclusion criteria were defined a priori. Any original study that discussed the impact of obesity on COVID-19 infections and vice versa was included. Given the limited evidence available on this topic, we included articles of all methodologies. Publications in non-English languages, non-clinical studies, and non-peer-reviewed studies (i.e., letters to the editor) were excluded. Our search yielded 2681 studies, as shown in the flow diagram (Fig. 1). After removal of duplicates, full-text articles were obtained if their abstracts were considered to be eligible. Each full-text article was assessed independently for final inclusion in this systematic review. The selection was performed by two authors (SC and KZ). In the event of conflicts of opinion, these were planned to be resolved by a third (SM).

\section{Data Extraction and Quality Assessment}

The quality of the studies was assessed independently using the Newcastle-Ottawa score (Table 1). Disagreements regarding quality assessment score for each study were resolved by consensus. All but one study scored highly across all domains and were assessed to be of good quality. However, due to the retrospective nature of the studies included in this review, an inherent systematic bias exists. Future studies should implement more rigorous methodologies in order to more confidently draw conclusions. SC and KZ independently extracted the following data from each article using a standardized study form: (1) study information, (2) geographic location, (3) research design, (4) study objective, (5) sample size, and (6) outcomes, including admission to the intensive care unit, severity of disease, use of mechanical ventilation, and mortality.

\section{Results}

\section{Study Characteristics (Table 2)}

We found seventeen studies investigating the relationship between obesity and the COVID-19 pandemic [3, 11-25]. Of these, eleven studies evaluated the impact of obesity on COVID-19 infection, including its role as a risk factor. The remaining six studies were on how the pandemic will worsen obesity [3, 22-26]. The included studies involved a total sample size of $8,534,639$ patients. All studies defined obesity as having a body mass index $(\mathrm{BMI}) \geq 30$ except for two studies performed in China on Asian populations. These investigations used a lower cut-off point for obesity of BMI $\geq 25$ and BMI $\geq 28$. One study used the Edmonton Obesity Staging System (EOSS) to classify its participants, noting that it is a better predictor of all-cause mortality in patients with obesity, as compared with BMI. All patients were reported to have an EOSS of 2-3 [12]. Four of the studies were policy statements from national and international organizations for bariatric surgery and hence deserved mention. The remainder was nonrandomized, observational studies.

\section{Discussion}

\section{Obesity in Pandemics}

To date, there is limited evidence elucidating the pathophysiological mechanisms linking obesity and severe COVID-19 disease. The novel coronavirus SARS-CoV-2 has $85 \%$ and $50 \%$ sequence similarity to known SARS-CoV-1 and MERS-CoV, respectively [27]. SARS-CoV-2 has been shown to gain access to the host via angiotensin-converting enzyme 2 (ACE-2) receptors which are upregulated in adipocyte and adipocyte-like cells such as pulmonary lipofibroblasts. This makes individuals with obesity and diabetes particularly vulnerable to severe lung infection and may explain the development of associated pulmonary fibrosis [28]. Moreover, low-grade systemic inflammation and end-organ damage seen in individuals with obesity are associated with the development of insulin resistance, type 2 diabetes, hypertension, atherosclerosis, dyslipidemia, and asthma - wellknown comorbidities that negatively affect the outcomes of 
Fig. 1 PRISMA diagram of studies


database searching $(n=2666)$

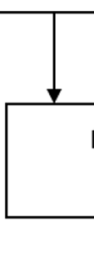

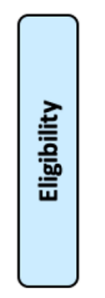

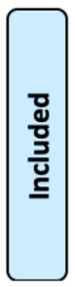

Records after duplicates removed $(n=1516)$

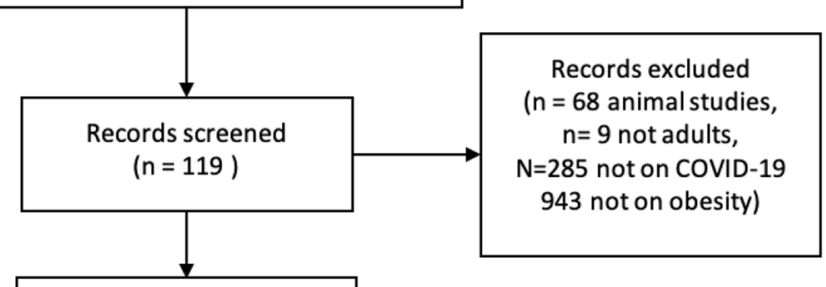

Full-text articles assessed for eligibility ( $n=116$ )

Additional records identified through other sources $(n=15)$ patients with COVID-19 [12]. Difficult airway management and prone positioning (critical in the treatment of ARDS) which are routinely encountered with elevated BMI further exacerbate the problem $[29,30]$.

This systematic review of the available evidence highlights the relationship between obesity and the COVID-19 pandemic. The included clinical characterization studies, case series, and case reports have shown that obesity is an independent, significant predictor of worse outcomes and increased complications from COVID-19 infections. Indeed, one study looked at factors associated with COVID-19 mortality by checking electronic health records of 17 million adult patients in the UK. It illustrated a positive association between patient death and degree of obesity (adjusted HR of 1.27 for BMI 3034.9 , increasing HR of 2.27 for $\mathrm{BMI} \geq 40$ ) [21]. Another study in a single French center analyzed 124 patients admitted in intensive care for SARS-CoV-2 and observed that obesity $(\mathrm{BMI}>30)$ and morbid obesity (BMI $>35)$ were present in $47.6 \%$ and $28.2 \%$ of cases, respectively. Furthermore, the need for invasive mechanical ventilation (IMV) significantly was shown to increase with BMI categories, independently of age, hypertension, and diabetes - the greatest proportion of those patients (85.7\%) had a BMI > 35 [20]. In the USA, a case series of 5700 patients with COVID-19 admitted to 12 hospitals in the state of New York showed that most common comorbidities exhibited were hypertension (56.6\%), obesity (41.7\%), and diabetes (33.8\%) [13]. Another study with 103 hospitalized COVID-19-postive patients (February 17-April 5 ) showed that $47.5 \%$ were obese. Morbid obesity (BMI $\geq 35)$ was associated with ICU admission, while patients who required IMV were more likely to have had heart disease, obesity (BMI $=30-34.9)$, or severe obesity [19].

These findings illustrate the increased vulnerability of the population with obesity in the COVID pandemic and mirror data from past pandemics. Increased adiposity has been implicated in higher rates of complications in MERS-CoV, SARSCoV-1, and H1N1 influenza pandemics, including development of acute respiratory distress syndrome (ARDS), acute lung injury (ALI), hospitalization, and mortality [31].

During the H1N1 swine flu of 2009, obesity was postulated to be an independent risk factor for increased morbidity and mortality in viral illnesses. In a study that spanned from April to August 2009 in California, Louie et al. found that over half of 534 adult hospitalized patients with H1N1 had a BMI $>30$. Of the 92 cases who died, $61 \%$ were obese [5]. Fezeu et al. revealed that $\mathrm{H} 1 \mathrm{~N} 1$ patients with $\mathrm{BMI}>40$ were twice as 
Table 1 Quality assessment of studies using the Newcastle-Ottawa scale

\begin{tabular}{|c|c|c|c|c|c|c|}
\hline Title & Authors & Study design & Selection & Comparability & Exposure & Quality \\
\hline $\begin{array}{l}\text { Obesity and COVID-19 severity in a designated } \\
\text { hospital in Shenzhen, China }\end{array}$ & Cai et al. & Retrospective study & $\bullet \bullet \bullet$ & $\bullet$ & $\bullet \bullet$ & Good \\
\hline $\begin{array}{l}\text { COVID-19 and the role of chronic inflammation } \\
\text { in patients with obesity }\end{array}$ & $\begin{array}{l}\text { Chiappetta } \\
\text { et al. }\end{array}$ & Retrospective study & $\bullet \bullet$ & $\bullet$ & $\bullet$ & Poor \\
\hline $\begin{array}{l}\text { Characteristics of emergency department patients } \\
\text { with COVID-19 at a single site in Northern } \\
\text { California: clinical observations and } \\
\text { public health implications }\end{array}$ & $\begin{array}{l}\text { Duanmu } \\
\text { et al. }\end{array}$ & $\begin{array}{l}\text { Cross-sectional } \\
\text { study }\end{array}$ & $\bullet \bullet$ & $\bullet$ & $\bullet \bullet$ & Good \\
\hline Obesity is a risk factor for greater COVID-19 severity & Goa et al. & Case-control study & $\bullet \bullet$ & $\bullet$ & $\bullet \bullet$ & Good \\
\hline $\begin{array}{l}\text { Association of Obesity with Disease Severity } \\
\text { among patients with COVID-19 }\end{array}$ & $\begin{array}{l}\text { Kalligeros } \\
\text { et al. }\end{array}$ & $\begin{array}{l}\text { Retrospective cohort } \\
\text { study }\end{array}$ & $\bullet \bullet$ & $\bullet$ & $\bullet \bullet \bullet$ & Good \\
\hline $\begin{array}{l}\text { OpenSAFELY: factors associated with COVID-19 } \\
\text { related hospital death in the linked electronic } \\
\text { health records of } 17 \text { million adult NHS patients }\end{array}$ & $\begin{array}{l}\text { Goldacre } \\
\text { et al. }\end{array}$ & $\begin{array}{l}\text { Retrospective cohort } \\
\text { study }\end{array}$ & $\bullet \bullet \bullet \bullet$ & $\bullet \bullet$ & $\bullet \bullet \bullet$ & Good \\
\hline $\begin{array}{l}\text { High prevalence of obesity in severe acute } \\
\text { respiratory syndrome coronavirus-2 } \\
\text { (SARS-Cov-2) requiring invasive } \\
\text { mechanical ventilation }\end{array}$ & $\begin{array}{l}\text { Simonnet } \\
\text { et al. }\end{array}$ & $\begin{array}{l}\text { Retrospective cohort } \\
\text { study }\end{array}$ & $\bullet \bullet$ & $\bullet$ & $\bullet \bullet \bullet$ & Good \\
\hline $\begin{array}{l}\text { Clinical and chest radiography features } \\
\text { determine patient outcomes in young } \\
\text { and middle age adults with COVID-19 }\end{array}$ & $\begin{array}{l}\text { Toussie } \\
\text { et al. }\end{array}$ & Retrospective study & $\bullet \bullet$ & $\bullet \bullet$ & $\bullet \bullet$ & Good \\
\hline $\begin{array}{l}\text { Clinical characteristics of } 145 \text { patients with corona virus disease } \\
2019 \text { (COVID-19) } \\
\text { in Taizhou, Zhejiang, China }\end{array}$ & Chen et al. & Retrospective study & $\bullet \bullet$ & $\bullet$ & $\bullet \bullet$ & \\
\hline $\begin{array}{l}\text { Bariatric surgical practice during the initial } \\
\text { phase of COVID-19 outbreak }\end{array}$ & $\begin{array}{l}\text { Aminian } \\
\text { et al. }\end{array}$ & $\begin{array}{l}\text { Retrospective cohort } \\
\text { study }\end{array}$ & $\bullet \bullet$ & $\bullet$ & $\bullet \bullet \bullet$ & Good \\
\hline $\begin{array}{l}\text { Effects of COVID-19 lockdown on lifestyle } \\
\text { behaviors in children with obesity living } \\
\text { in Verona, Italy: a long study }\end{array}$ & $\begin{array}{l}\text { Pietrobelli } \\
\text { et al. }\end{array}$ & $\begin{array}{l}\text { Longitudinal cohort } \\
\text { study }\end{array}$ & $\bullet \bullet$ & $\bullet$ & $\bullet \bullet$ & \\
\hline
\end{tabular}

likely to be admitted to the intensive care unit, with a higher mortality rate than those with a lower BMI [6].

The outbreaks of MERS and SARS in the early 2000s further established obesity as being positively associated with mortality, along with male gender, older age, hypertension, diabetes, COPD, and chronic heart diseases [9, 32, 33]. The clinical features of both of these coronaviruses, SARS-CoV-1, and MERS$\mathrm{CoV}$ can range from asymptomatic or mild disease to ARDS and multi-organ failure. However, $75 \%$ of MERS cases are associated with underlying comorbidities, with a mortality rate of MERS of $60 \%$ in this subgroup, while only $10-30 \%$ of SARS patients have underlying health conditions with a mortality rate of $46 \%$ within this subgroup [34]. Given that the novel coronavirus SARS-CoV-2 has $85 \%$ and $50 \%$ sequence similarity to the SARS-CoV-1 and MERS-CoV, respectively [27], it comes as no surprise that the diseases caused by these viruses share similar clinical features [35].

\section{Individuals with Obesity May Be More Infectious}

Several human and animal studies have demonstrated a positive correlation between infectivity and increased weight. Maier et al. demonstrated that symptomatic individuals with obesity shed influenza A particles up to $104 \%$ longer than their lean counterparts [36]. Similarly, in a study of 178 young adults, Yan et al. concluded that the concentration of viral RNA found in aerosols from collected breath correlated positively with BMI [37]. The obesity microenvironment may also be conducive to the development of more virulent viral strains. For example, obese mice models infected with influenza were observed to have a decreased type I interferon response and had increased viral replication as compared with non-obese mice [38]. There is a paucity of evidence on the infectivity of individuals with obesity in the COVID-19 pandemic, but extrapolations can be made from investigations on other viruses. While the pathophysiology of SARS-CoV2 infection has not been completely elucidated, it has been proposed that the virus gains entry into cells through ACE2dependent mechanisms, much like SARS-CoV and human respiratory coronavirus NL63 [39]. It is spread by human-tohuman transmission via droplets, aerosolized particles, and direct contact [40]. Infection has been estimated to have an incubation time varying from 2 to 14 days, with a mean of 6.4 days [40, 41]. Taking into considering prolonged viral shedding and increased viral load in expired air in persons with obesity, longer quarantine periods should be considered 


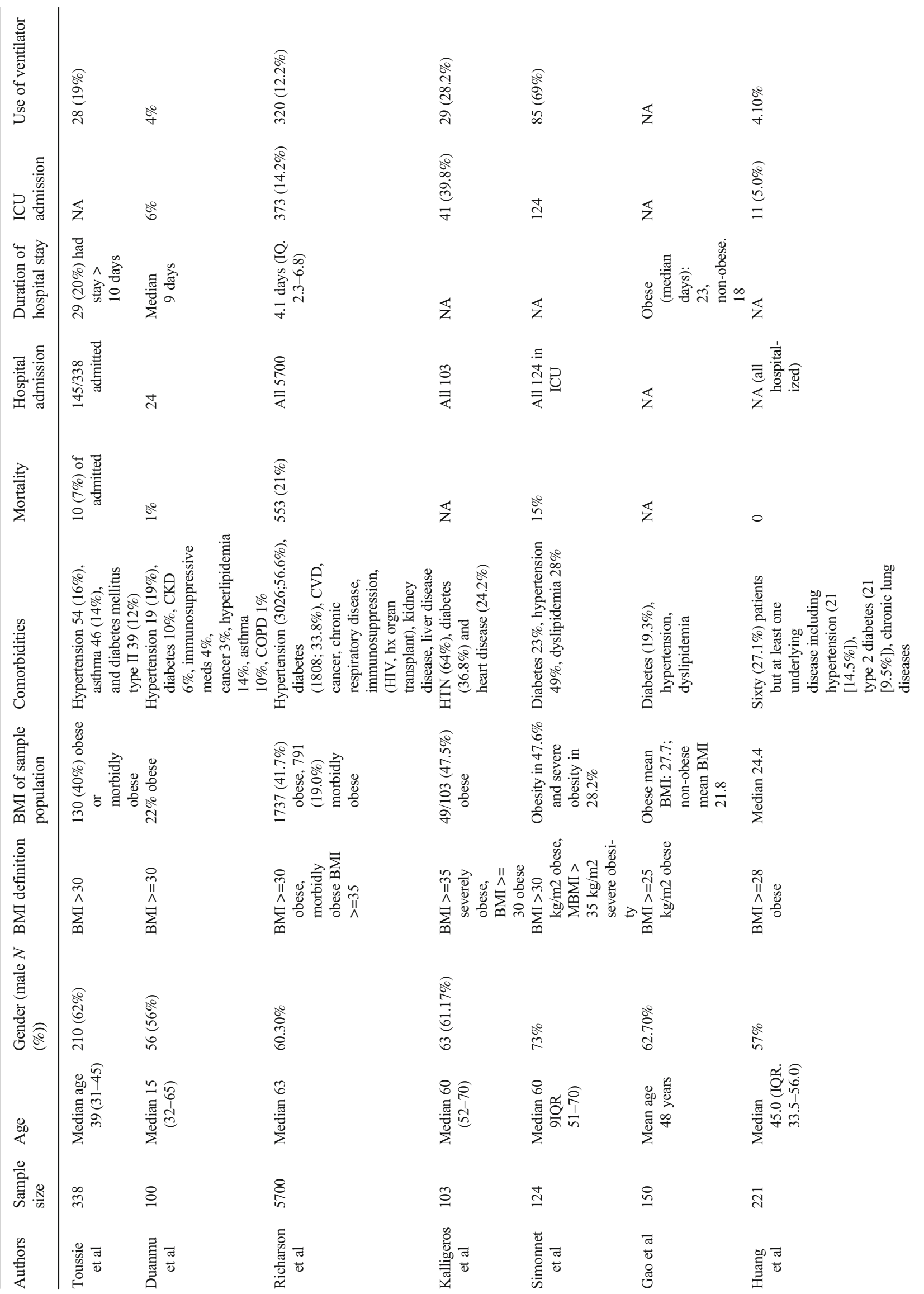




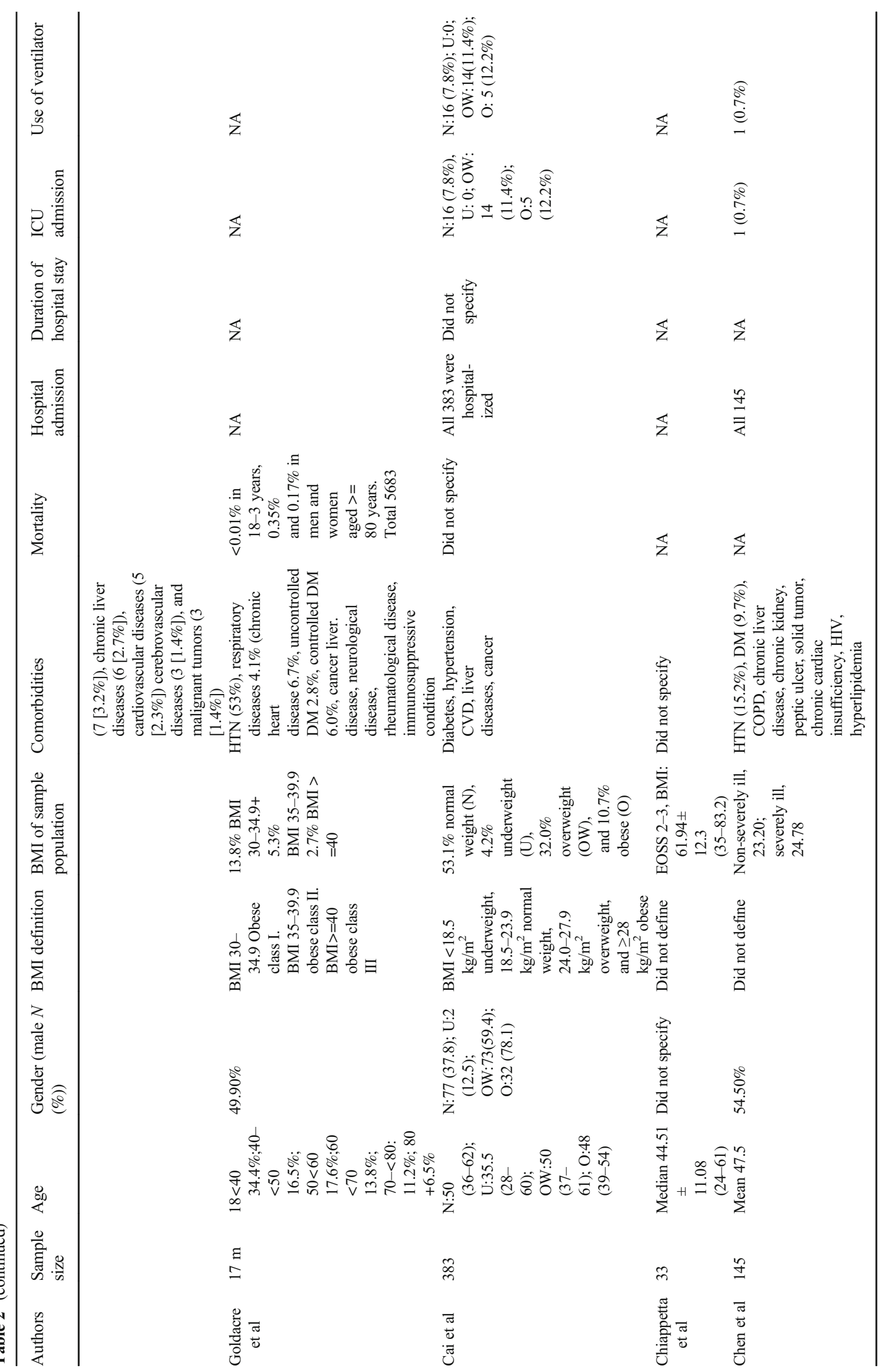


in individuals with increased adiposity as compared with their lean counterparts [42].

\section{Viral Infections May Induce Obesity}

The association between obesity and viral infection is not unidirectional. Certain infections by pathogens like adenovirus 36 (Ad36) have been demonstrated to induce obesity. In a systematic review published in 2020, Kim et al. conclude that Ad36 infection increases adipogenesis (through hypertrophy and hyperplasia) in animals and is associated with human obesity. Moreover, Ad36 infection was shown to induce acute and chronic inflammation leading to angiogenesis in fatty tissues [43]. Another systematic review by $\mathrm{Xu}$ et al. concludes that Helicobacter pylori infection may be a risk factor for the development of obesity [44]. However, a causal relationship cannot be established due to the nature of the study design of the included studies.

\section{Indirect Impact of COVID19 on the Population Suffering from Obesity and Obesity Services}

We have recognized that obesity is a risk factor for poor outcomes in COVID-19 infection [21, 45]. However, it is inevitable that the pandemic will only exacerbate the existing levels of obesity for several reasons. Firstly, the lifestyle of the average individual during a state of social isolation and global unrest will drastically change. Specifically, in the early phases of the pandemic and during lockdown measures, there will likely be a tendency towards an unhealthy diet coupled with a sedentary lifestyle. Over a longer time, this may lead to considerable weight gain for most people. Secondly, the reallocation of hospital resources from elective surgeries to managing COVID-19 patients has led to the nationwide pause of most bariatric surgery as well as most other multidisciplinary services that comprise of the tier 3 weight management programs [24]. This is not only to free up inpatient capacity and redirect healthcare workers towards managing COVID-19 patients but also to avoid intraoperative risks of viral contagion among patients and staff [22]. Hence, there is a pre-existing level of obesity that we have not managed yet. In combination, we predict a rise in obesity and its complications in the postCOVID era [46].

Globally, the majority of governments have instituted a "lockdown" approach in an effort to limit the transmission of COVID-19 cases. While this has been proven to be effective as containment measures, there are multiple negative effects of this approach. From an obesity perspective, it is highly likely that the cessation of active lifestyles will lead to an increase in weight gain among a significant proportion of the population [26]. This can be attributed to a reduction in physical exercise as well as poorer dietary lifestyle. In the early phases of the outbreak, panic buying and stockpiling depleted most stores of perishable healthy food items, including meat, fruits, and vegetables [47]. These reactions had severe repercussions on both food access and utilization [48]. Consequently, most people had to rely on unhealthy food items as sustenance. Previously, Scully et al. had shown that both lockdown and confinement would also lead to erratic dietary patterns and frequent snacking, both of which are associated with higher caloric intake and increased risk of obesity [49]. Furthermore, studies from China showed a negative impact on psychological health, which has previously been linked to unhealthy dietary patterns and poor quality of the diet $[23,50,51]$. Hence, the current lockdown is likely to increase the prevalence of obesity, and we should actively seek measures to overcome them.

The COVID-19 crisis has led to the cessation of most elective surgical procedures globally at different times. In the UK, NHS England has asked for elective procedures to be halted for 3 months starting from April 15, 2020 [52, 53]. Accordingly, early guidelines from the International Federation for the Surgery of Obesity and metabolic disorders (IFSO) recommended postponing any bariatric procedure [24]. But, delaying bariatric surgery extends the progression of metabolic complications of obesity, including type 2 diabetes, obesity hypoventilation syndrome, obesity-associated heart failure, and cancers [54-59]. This directly increases the disease burden among patients. For example, previous modeling work and the multi-cantered Swedish Obesity Study have consistently showed long-standing disease as a strong predictor of disease remission [60-62]. The impact of canceling elective bariatric surgery will be expensive. Previous economic analyses have shown that diseases that can be corrected with surgery are more cost-effective than medical management. For example, the management of type 2 diabetes with several medications is far more costly than bariatric surgery. Hence, delaying surgery for these patients will make it less costsaving over time.

Currently, there is no large-scale data on the outcomes of bariatric surgery during the COVID-19 pandemic, and studies are ongoing to evaluate the impact of disruption of bariatric services on patient care and quality of life. However, the largest international cohort study involving surgical patients reported that complications and mortality were observed at a higher rate compared in specific patient cohorts, specifically emergency surgery, male gender, age above 70 years, and a higher ASA grade. Compared with pre-pandemic levels, morbidity and mortality is higher across all types of surgery according to this study. However, the delaying of surgery probably also leads to disease progression [63]. Hence, a realistic and safe approach will be to prioritize patients who will most benefit from surgery without exposing them to an unnecessarily high risk. 
There are several solutions for the aforementioned issues. Firstly, there should be a coordinated effort from governments and food and beverage industry to ensure an adequate supply chain to prevent food insecurity. There needs to be increased public awareness about the "lockdown lifestyle" that can make them obese and provide strategies to avoid it. Already, the WHO has provided a list of exercises that can be performed at home to stay physically active [64]. Secondly, in the context of a long backlog of operations and patients with higher likelihood of complications, it is possible that there will be a shortage of staff and hospital beds to accommodate this surge. Traditionally, patients have been listed for surgery on a first-come-first-serve basis, prioritized on clinical need. Now, we must generate guidelines for prioritizing patients based on disease severity, taking into account any co-existing microvascular and macrovascular complications of obesity (indicators of organ dysfunction) [65]. For example, the Diabetes Surgery Summit (DSS) recommends that patients using insulin and patients with disease duration longer than 5 years be prioritized [25]. In the meanwhile, patients should be optimized for surgery and ensure that their weight and metabolism is controlled through lifestyle and pharmacological measures. Surgery should be expedited for patients not responding to such conservative measures. Obesity management/bariatric surgical teams must be advocates for their patients during these difficult times; otherwise, there is a significant risk of the patients' needs being ignored due to continued public perception that obesity is still a choice and not a disease [66]. Through these measures, we may be able to mitigate the afterburn of COVID-19 on the bariatric population.

\section{Conclusion}

COVID-19 is an unprecedented viral pandemic with high transmissibility. Obesity, a pandemic in itself, is an independent factor for having a worse outcome among COVID19 patients. The dual pandemic - CoVesity - will have a detrimental outcome in the short, medium, and long term. We should aim at a phased and safe return of obesity/ bariatric services based on expert consensus, guidelines, and recommendations from the relevant national and international bodies. There are already safe and reproducible proven interventions for the obesity pandemic that existed prior to COVID-19.

Authors' Contributions SP conceived the idea for the study. KZ, SC, and SM designed the study. KZ and SC performed the search, screening, data extraction, analysis, and interpretation. KZ, SC, SP, SM, KM, PS, RA, PS, and JK drafted the manuscript. SP is study guarantor. All authors reviewed the final manuscript and agreed to be accountable for all aspects of the work and approved the final manuscript for submission. The corresponding author attests that all listed authors meet authorship criteria and that no others meeting the criteria have been omitted.

\section{Compliance with Ethical Standards}

Conflict of Interest The authors declare that they have no conflict of interest.

Ethical Approval For this type of study, formal consent is not required.

Informed Consent Informed consent does not apply.

Open Access This article is licensed under a Creative Commons Attribution 4.0 International License, which permits use, sharing, adaptation, distribution and reproduction in any medium or format, as long as you give appropriate credit to the original author(s) and the source, provide a link to the Creative Commons licence, and indicate if changes were made. The images or other third party material in this article are included in the article's Creative Commons licence, unless indicated otherwise in a credit line to the material. If material is not included in the article's Creative Commons licence and your intended use is not permitted by statutory regulation or exceeds the permitted use, you will need to obtain permission directly from the copyright holder. To view a copy of this licence, visit http://creativecommons.org/licenses/by/4.0/.

\section{References}

1. WHO Timeline - COVID-19: World Health Organization; 2020 [updated April 27, 2020. Available from: https://www.who.int/ news-room/detail/27-04-2020-who-timeline\%2D\%2D-covid-19.

2. Jordan RE, Adab P, Cheng KK. Covid-19: risk factors for severe disease and death. BMJ. 2020;368:m1198.

3. Fruhbeck G, Baker JL, Busetto L, et al. European Association for the study of obesity position statement on the global COVID-19 pandemic. Obes Facts. 2020;13(2):292-6.

4. Obesity and Overweight [updated April 01, 2020. Available from: https://www.who.int/en/news-room/fact-sheets/detail/obesity-andoverweight.

5. Louie JK, Acosta M, Samuel MC, et al. A novel risk factor for a novel virus: obesity and 2009 pandemic influenza A (H1N1). Clin Infect Dis. 2011;52(3):301-12.

6. Fezeu L, Julia C, Henegar A, et al. Obesity is associated with higher risk of intensive care unit admission and death in influenza $\mathrm{A}$ (H1N1) patients: a systematic review and meta-analysis. Obes Rev. 2011;12(8):653-9.

7. Kwong JC, Campitelli MA, Rosella LC. Obesity and respiratory hospitalizations during influenza seasons in Ontario, Canada: a cohort study. Clin Infect Dis. 2011;53(5):413-21.

8. Moser JS, Galindo-Fraga A, Ortiz-Hernandez AA, et al. Underweight, overweight, and obesity as independent risk factors for hospitalization in adults and children from influenza and other respiratory viruses. Influenza Other Respir Viruses. 2019;13(1):39.

9. Halim AA, Alsayed B, Embarak S, et al. Clinical characteristics and outcome of ICU admitted MERS corona virus infected patients. Egypt J Chest Dis Tuberc. 2016;65(1):81-7.

10. Moher D, Liberati A, Tetzlaff J, et al. Preferred reporting items for systematic reviews and meta-analyses: the PRISMA statement. BMJ. 2009;339:b2535.

11. Duanmu Y, Brown IP, Gibb WR, et al. Characteristics of emergency department patients with COVID-19 at a single site in northern California: clinical observations and public health implications. Acad Emerg Med. 2020;27:505-9. 
12. Chiappetta S, Sharma AM, Bottino V, et al. COVID-19 and the role of chronic inflammation in patients with obesity. Int J Obes. 2020;44:1790-2.

13. Cai Q, Chen F, Wang T, et al. Obesity and COVID-19 severity in a designated hospital in Shenzhen. Diabetes Care: China; 2020.

14. Gao F, Zheng KI, Wang XB, et al. Obesity is a risk factor for greater COVID-19 severity. Diabetes Care. 2020;43:e72-4.

15. Toussie D, Voutsinas N, Finkelstein M, et al. Clinical and chest radiography features determine patient outcomes in young and middle age adults with COVID-19. Radiology. 2020;201754

16. Huang R, Zhu L, Xue L, et al. Clinical findings of patients with coronavirus disease 2019 in Jiangsu province, China: a retrospective, multi-center study. PLoS Negl Trop Dis. 2020;14(5): e0008280.

17. Chen Q, Zheng Z, Zhang C, Zhang X, Wu H, Wang J, et al. Clinical characteristics of 145 patients with corona virus disease 2019 (COVID-19) in Taizhou, Zhejiang, China. Infection. 2020.

18. Richardson S, Hirsch JS, Narasimhan M, et al. Presenting characteristics, comorbidities, and outcomes among 5700 patients hospitalized with COVID-19 in the New York City area. JAMA. 2020;323:2052.

19. Kalligeros M, Shehadeh F, Mylona EK, Benitez G, Beckwith CG, Chan PA, et al. Association of obesity with disease severity among patients with COVID-19. Obesity (Silver Spring). 2020.

20. Simonnet A, Chetboun M, Poissy J, Raverdy V, Noulette J, Duhamel A, et al. High prevalence of obesity in severe acute respiratory syndrome coronavirus-2 (SARS-CoV-2) requiring invasive mechanical ventilation. Obesity (Silver Spring). 2020.

21. The OpenSAFELY Collaborative, Williamson EW, AJ, Bhaskaran $\mathrm{KJ}$, Bacon S, Bates C et al. Open SAFELY: factors associated with COVID-19 related hospital death in the linked electronic health records of 17 million adult NHS patients. medRxiv. 2020.

22. Aminian A, Kermansaravi M, Azizi S, et al. Bariatric surgical practice during the initial phase of COVID-19 outbreak. Obes Surg. 2020;30:3624-7.

23. Sockalingam S, Leung SE, Cassin SE. The impact of COVID-19 on bariatric surgery: re-defining psychosocial care. Obesity (Silver Spring). 2020

24. Yang WW, C.; Shikora, S.; Kow, L. Recommendations for metabolic and bariatric surgery during the COVID-19 pandemic from IFSO. Obes Surg. 2020;30:2071-3.

25. Rubino F, Cohen RV, Mingrone G, et al. Bariatric and metabolic surgery during and after the COVID-19 pandemic: DSS recommendations for management of surgical candidates and postoperative patients and prioritisation of access to surgery. Lancet Diabetes Endocrinol. 2020;8:640-8.

26. Pietrobelli A, Pecoraro L, Ferruzzi A, Heo M, Faith M, Zoller T, et al. Effects of COVID-19 lockdown on lifestyle behaviors in children with obesity living in Verona, Italy: a longitudinal study. Obesity (Silver Spring). 2020.

27. Lu R, Zhao X, Li J, et al. Genomic characterisation and epidemiology of 2019 novel coronavirus: implications for virus origins and receptor binding. Lancet. 2020;395(10224):565-74.

28. Kruglikov IL, Scherer PE. The role of adipocytes and adipocytelike cells in the severity of COVID-19 infections. Obesity (Silver Spring). 2020

29. Pelosi P, Gregoretti C. Perioperative management of obese patients. Best Pract Res Clin Anaesthesiol. 2010;24(2):211-25.

30. Jose RJ, Manuel A, et al. Obesity (Silver Spring). 2020;28(6):1007.

31. Hendrickson CM, Matthay MA. Viral pathogens and acute lung injury: investigations inspired by the SARS epidemic and the 2009 H1N1 influenza pandemic. Semin Respir Crit Care Med. 2013;34(4):475-86.

32. Badawi A, Ryoo SG. Prevalence of comorbidities in the Middle East respiratory syndrome coronavirus (MERS-CoV): a systematic review and meta-analysis. Int J Infect Dis. 2016;49:129-33.
33. Morra ME, Van Thanh L, Kamel MG, et al. Clinical outcomes of current medical approaches for Middle East respiratory syndrome: a systematic review and meta-analysis. Rev Med Virol. 2018;28(3): e1977.

34. Dyall J, Gross R, Kindrachuk J, et al. Middle East respiratory syndrome and severe acute respiratory syndrome: current therapeutic options and potential targets for novel therapies. Drugs. 2017;77(18):1935-66.

35. Petrosillo N, Viceconte G, Ergonul O, et al. COVID-19, SARS and MERS: are they closely related? Clin Microbiol Infect. 2020;26(6): 729-34.

36. Maier HE, Lopez R, Sanchez N, et al. Obesity increases the duration of influenza a virus shedding in adults. J Infect Dis. 2018;218(9):1378-82.

37. Yan J, Grantham M, Pantelic J, et al. Infectious virus in exhaled breath of symptomatic seasonal influenza cases from a college community. Proc Natl Acad Sci U S A. 2018;115(5):1081-6.

38. Honce R, Karlsson EA, Wohlgemuth N, Estrada LD, Meliopoulos VA, Yao J, et al. Obesity-related microenvironment promotes emergence of virulent influenza virus strains. mBio. 2020;11(2).

39. Abdul-Rasool S, Fielding BC. Understanding human coronavirus HCoV-NL63. Open Virol J. 2010;4:76-84.

40. Meselson M. Droplets and aerosols in the transmission of SARSCoV-2. N Engl J Med. 2020;382:2063.

41. Lai CC, Shih TP, Ko WC, et al. Severe acute respiratory syndrome coronavirus 2 (SARS-CoV-2) and coronavirus disease-2019 (COVID-19): the epidemic and the challenges. Int J Antimicrob Agents. 2020;55(3):105924.

42. Luzi L, Radaelli MG. Influenza and obesity: its odd relationship and the lessons for COVID-19 pandemic. Acta Diabetol. 2020;57: 759-64.

43. Kim J, Na H, Kim JA, et al. What we know and what we need to know about adenovirus 36-induced obesity. Int J Obes. 2020;44: 1197-209.

44. $\mathrm{Xu} \mathrm{X,} \mathrm{Li} \mathrm{W,} \mathrm{Qin} \mathrm{L,} \mathrm{et} \mathrm{al.} \mathrm{Relationship} \mathrm{between} \mathrm{helicobacter} \mathrm{pylori}$ infection and obesity in Chinese adults: a systematic review with meta-analysis. PLoS One. 2019;14(9):e221076.

45. Report on COVID-19 in critical care. Intensive Care National Audit and Research Centre; 2020.

46. Patterson R, McNamara E, Tainio M, et al. Sedentary behaviour and risk of all-cause, cardiovascular and cancer mortality, and incident type 2 diabetes: a systematic review and dose response metaanalysis. Eur J Epidemiol. 2018;33(9):811-29.

47. Galanakis CM. The food systems in the era of the coronavirus (COVID-19) pandemic crisis. Foods. 2020;9(4).

48. Niles MT, Bertmann F, Morgan E, Wentworth T, Biehl E. Food Access and Security During Coronavirus: A Vermont Study. Coll Agric Life Sci Fac. 2020.

49. Scully M, Dixon H, Wakefield M. Association between commercial television exposure and fast-food consumption among adults. Public Health Nutr. 2009.

50. Li Z, Ge J, Yang M, et al. Vicarious traumatization in the general public, members, and non-members of medical teams aiding in COVID-19 control. Brain Behav Immun. 2020;

51. Anton SD, Miller PM. Do negative emotions predict alcohol consumption, saturated fat intake, and physical activity in older adults? Behav Modif. 2005.

52. COVID-19: Good Practice for Surgeons and Surgical Teams Royal College of Surgeons; 2020 [Available from: https://www.rcseng.ac. uk/standards-and-research/standards-and-guidance/good-practiceguides/coronavirus/covid-19-good-practice-for-surgeons-andsurgical-teams/.

53. Recovery of surgical services during and after COVID-19 Royal College of Surgeons; 2020 [Available from: https://www.rcseng.ac. uk/coronavirus/recovery-of-surgical-services/. 
54. Ikramuddin S, Korner J, Lee WJ, et al. Lifestyle intervention and medical management with vs without roux-en-Y gastric bypass and control of hemoglobin A1c, LDL cholesterol, and systolic blood pressure at 5 years in the diabetes surgery study. JAMA. 2018;319(3):266-78.

55. O'Brien R, Johnson E, Haneuse S, et al. Microvascular outcomes in patients with diabetes after bariatric surgery versus usual care: a matched cohort study. Ann Intern Med. 2018;169(5):300-10.

56. Schauer DP, Feigelson HS, Koebnick C, et al. Bariatric surgery and the risk of cancer in a large multisite cohort. Ann Surg. 2019;269(1):95-101.

57. Schauer PR, Bhatt DL, Kirwan JP, et al. Bariatric surgery versus intensive medical therapy for diabetes - 5-year outcomes. N Engl J Med. 2017;376(7):641-51.

58. Lassailly G, Caiazzo R, Buob D, et al. Bariatric surgery reduces features of nonalcoholic steatohepatitis in morbidly obese patients. Gastroenterology. 2015;149(2):379-88. quiz e15-6.

59. Mingrone G, Panunzi S, De Gaetano A, et al. Bariatric-metabolic surgery versus conventional medical treatment in obese patients with type 2 diabetes: 5 year follow-up of an open-label, singlecentre, randomised controlled trial. Lancet. 2015;386(9997):96473.

60. Still CD, Wood GC, Benotti P, et al. Preoperative prediction of type 2 diabetes remission after roux-en-Y gastric bypass surgery: a retrospective cohort study. Lancet Diabetes Endocrinol. 2014;2(1): $38-45$.
61. Sjoholm K, Pajunen P, Jacobson P, et al. Incidence and remission of type 2 diabetes in relation to degree of obesity at baseline and 2 year weight change: the Swedish obese subjects (SOS) study. Diabetologia. 2015;58(7):1448-53.

62. Aron-Wisnewsky J, Sokolovska N, Liu Y, et al. The advancedDiaRem score improves prediction of diabetes remission 1 year post-roux-en-Y gastric bypass. Diabetologia. 2017;60:1892-902.

63. Collaborative CO. Mortality and pulmonary complications in patients undergoing surgery with perioperative SARS-CoV-2 infection: an international cohort study. Lancet. 2020;396(10243):2738 .

64. Be Active during COVID-19: World Health Organization; 2020 [

65. Purkayastha S SP, Salminen P, Ramos A, Mahawar K. Bariatric surgery: what next to address a pandemic within a pandemic? PanSurg Webinar. 2020.

66. Purkayastha S SP, Salminen P, Ramos A, Mahawar K. Times letters: Vulnerable pupils face 'Covid learning slide': The Times UK; 2020 [updated May 19. Available from: https://www.thetimes.co. uk/article/times-letters-vulnerable-pupils-face-covid-learning-slide$65 \mathrm{vps} 1 \mathrm{p} 73$.

Publisher's Note Springer Nature remains neutral with regard to jurisdictional claims in published maps and institutional affiliations. 